\title{
ATROPHIC NONUNION OF THE CLAVICLE
}

\author{
TREATMENT BY COMPRESSION PLATE, LAG-SCREW FIXATION AND BONE GRAFT
}

MARTIN I. BOYER, TERRY S. AXELROD

From Sunnybrook Health Science Centre, Ontario, Canada

\begin{abstract}
We describe a new surgical treatment of atrophic nonunion of the clavicle. The nonunion is excised by cuts at $45^{\circ}$ to the long axis and repair uses $3.5 \mathrm{~mm}$ pelvic reconstruction or dynamic compression plates, with a lag screw to provide interfragmentary compression. The site is grafted with cancellous bone.

We have been successful in all seven patients, with early return to normal function. The consequent narrowing of the shoulder girdle is fully acceptable for appearance and function.
\end{abstract}

J Bone Joint Surg [Br] 1997;79-B:301-3.

Received 27 June 1996; Accepted 19 September 1996

There is controversy concerning the management of symptomatic nonunion of the clavicle. The options include excision of the site, ${ }^{1-3}$ interosseous wiring with a bone graft, $^{4}$ and intramedullary fixation. ${ }^{5,6}$ Interfragmentary screw fixation and dynamic compression plating with various combinations of cortical ${ }^{7}$ or cancellous autograft ${ }^{1-3,8-10}$ or allograft ${ }^{7}$ have also been used.

The need to restore the length of the clavicle and the width of the shoulder girdle is emphasised by those who advocate an interposed iliac-crest graft. This may not be necessary from either the functional or cosmetic viewpoints.

We report the reconstruction of seven clavicular pseudarthroses by primary excision of the nonunion, lag-screw fixation, compression plating using the $\mathrm{AO}$ technique and cancellous grafting with iliac-crest bone.

M. I. Boyer, MD, MSc, FRCS C, Clinical Fellow, Upper Extremity Service

T. S. Axelrod, MD, MSc, FRCS C, Chief, Division of Orthopaedics

Division of Orthopaedic Surgery, Sunnybrook Health Science Centre,

2075 Bayview Avenue, A-315 Toronto, Ontario, Canada M4N 3M5.

Correspondence should be sent to Dr T. S. Axelrod.

(c)1997 British Editorial Society of Bone and Joint Surgery 0301-620X/97/27044 \$2.00

\section{PATIENTS AND METHODS}

We reviewed retrospectively seven consecutive patients treated for nonunion of the clavicle since September 1992. We recorded their age, gender, occupation at the time of injury, arm dominance, the initial fracture pattern and treatment, and the time elapsed between the injury and operative treatment. All seven patients were interviewed, and examined by one author (MIB) who recorded the range of movement, grip and pinch strength, and the width of the shoulder girdle on both sides. We used a questionnaire (DASH: Disabilities of the Arm, Shoulder and Hand) to allow patients to record upper-limb function.

Operative technique. A sabre-cut incision is used, unless the scar of a previous procedure is present, which is reopened. Any metal implant is removed; the site of nonunion is identified and exposed circumferentially. An oscillating saw is used to make oblique parallel cuts completely excising the area of nonunion down to bleeding bone. This method minimises shortening and increases the surface area of bone-to-bone contact. Care is taken to avoid thermal injury to bone.

The cut ends of the clavicle are compressed together using small reduction forceps, and the oblique osteotomy held with pointed AO reduction forceps. A plate is then contoured to fit the upper surface of the clavicle, the shape of which can easily be matched by a $3.5 \mathrm{~mm}$ pelvic reconstruction plate. The first screw is placed across the osteotomy, drilled to provide compression as a lag screw. The other screws are placed and the area around the osteotomy is packed with cancellous bone graft from the iliac crest. The wound is closed over a drain (medium size; Haemovac). All patients had interfragmentary compression with a lag screw; two had a 7-hole $3.5 \mathrm{~mm}$ LC-DC plate, one had a 7-hole, one an 8-hole and three a 9-hole pelvic reconstruction plate. All had one lag screw through the plate except for one 9-hole plating in which a lag screw was inserted in an anteroposterior direction outside the plate.

A shoulder splint is used for comfort for the first few weeks, but gentle pendulum exercises start when postoperative pain has settled. Active movement of the shoulder starts only when there is early evidence of radiographic union, usually at six weeks. Strengthening exercises for the shoulder muscles are started at two to three months. 


\section{RESULTS}

Of the seven patients, five were male, and two were female. The dominant arm was involved in three. One patient's job required heavy use of his arm, five had work that was not physically demanding and one was a student. Their average age was 38 years (17 to 55 ).

Two had had primary operations for their fracture, one by internal fixation for an open injury and one by primary plating after a clavicular osteotomy for the removal of a schwannoma of the brachial plexus. The other five had been treated conservatively for from four to 12 months.

One of the original fractures was comminuted but a single site of nonunion was seen on plain radiographs or tomographs in all cases before operation (Figs 1 and 2).

The average time to union was nine weeks (6 to 12), and all but the patient who had removal of a schwannoma returned to full function and employment. All had full pain relief and none had limitation of activity. No patient was dissatisfied with their appearance, despite one narrower shoulder girdle. One patient had occasional mild dress problems but accepted this easily.

The range of shoulder movement was equal on both sides and the average reduction in length of the clavicle and therefore of the width of the shoulder girdle was $1.5 \mathrm{~cm}(0$ to 2). Excluding the patient with a residual neurological disability pinch-grip strengths were only slightly reduced on the operated side. The DASH questionnaire confirmed that no patients had any difficulties with shoulder-related activities, such as heavy household chores, washing the hair or back, or putting on tight clothing.

\section{DISCUSSION}

Most closed fractures of the clavicle are managed conservatively and often unite with some shortening. ${ }^{11}$ Nonunion is rare, but associated factors include high energy or open injuries, inadequate immobilisation and closed fractures treated by operation.

Painless nonunion rarely requires treatment, unless neurovascular symptoms are present. Pain or neurovascular compromise require treatment by operation, and many options have been described.

Partial removal of the clavicle has been described for nonunion associated with a thoracic outlet syndrome and local pain, ${ }^{1-3}$ but may cause dissatisfaction because of the appearance of the shoulder. Intramedullary pinning may be combined with cancellous bone or onlay iliac-crest grafting, ${ }^{5,6}$ but this is difficult because the pin has to pass through the thin atrophic ends of the bone close to neurovascular structures. Such pinning may cause distraction, and migration of the thin Kirschner wires is common.

Interosseous wiring with iliac-crest bone graft has been described, ${ }^{4}$ as has simple lag-screw fixation with bone grafting. Neither method gives full stability.

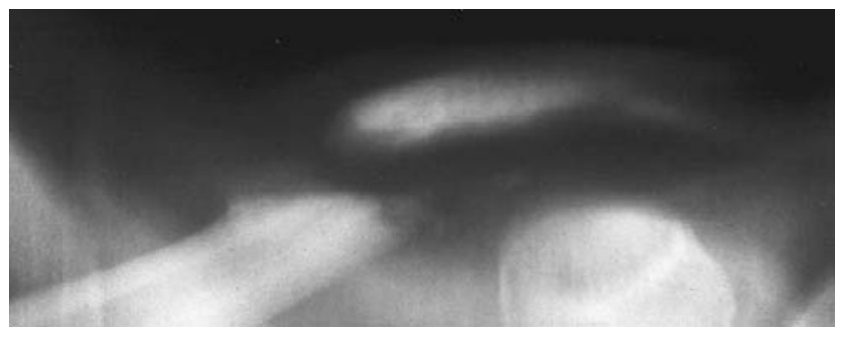

Fig. 1a

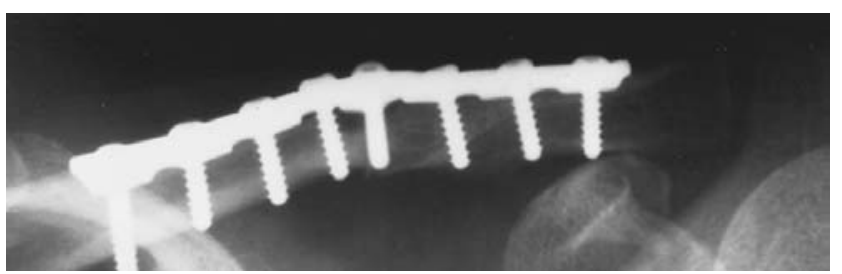

Fig. 1b

Anteroposterior tomogram of an atrophic nonunion in a 44-year-old woman, one year after the injury (a). Healing at two months (b).

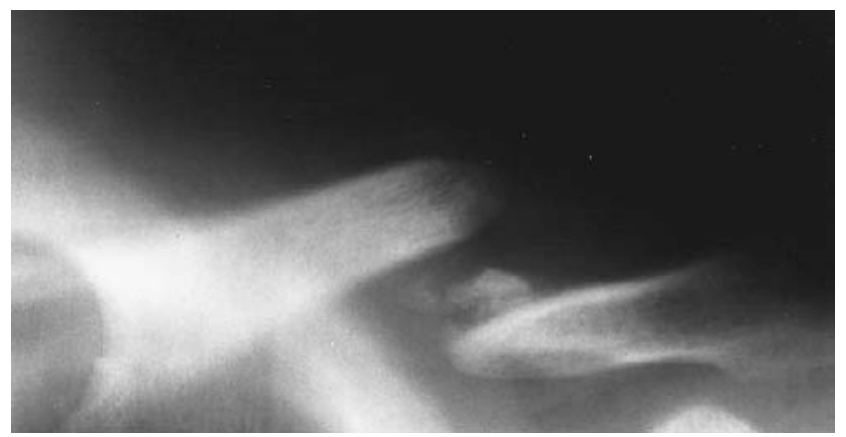

Fig. 2a

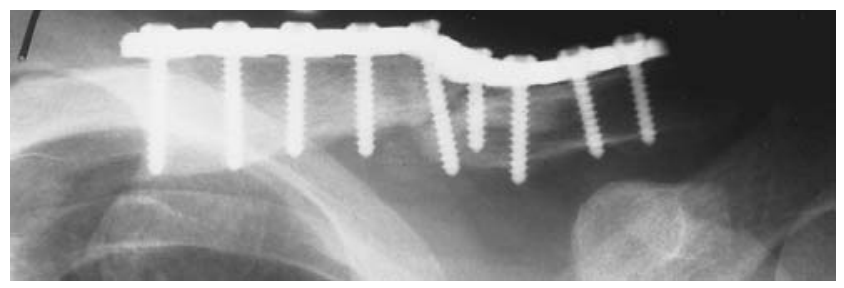

Fig. 2b

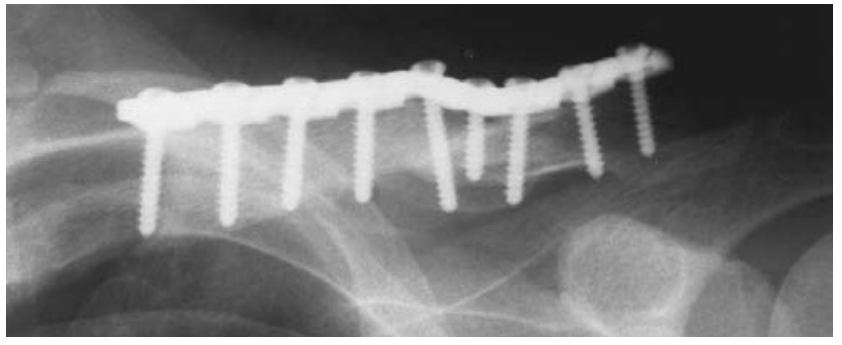

Fig. 2c

Anteroposterior tomogram in a 34-year-old firefighter (a). At six weeks there is early callus (b), with union at three months (c). 
Internal fixation with an AO semitubular plate with or without cancellous bone grafting, cortical autografting or allografting has been reported. ${ }^{8,10}$ The screw heads are prominent under the skin, however, and the thin plate may not provide adequate stability.

For atrophic nonunion with large gaps, tricortical iliaccrest interposition grafts with AO dynamic 3.5 compression plating have been used, ${ }^{3}$ but this leaves two fracture sites and is technically demanding.

\section{REFERENCES}

1. Eskola A, Vainionpaa S, Myllyen P, Patiala H, Rokkanen P. Surgery for ununited clavicle fracture. Acta Orthop Scand 1986; 57:366-7.

2. Connolly JF, Dehne R. Nonunion of the clavicle and thoracic outlet syndrome. J Trauma 1989;29:1127-33.

3. Jupiter JB, Leffert RD. Nonunion of the clavicle: associated complications and surgical management. J Bone Joint Surg [Am] 1987; 69-A:753-60.

4. Wachsmuth W. In Allgemeine und Spezielle Operationslehre. Berlin: Springer Verlag, 1956:375.

5. Sakellarides H. Pseudarthrosis of the clavicle: a report of twenty cases. J Bone Joint Surg [Am] 1961;43-A:130-8.

6. Taylor AR. Nonunion of fractures of the clavicle: a review of 31 cases. J Bone Joint Surg [Br] 1969;51-B:568-9.
The technique which we describe respects $\mathrm{AO}$ principles $^{12}$ for the treatment of nonunion, allows early postoperative mobilisation of adjacent joints, and minimises morbidity at the donor site of the bone graft. The lack of restoration of shoulder width has proved to be cosmetically acceptable and gives excellent function.

No benefits in any form have been received or will be received from a commercial party related directly or indirectly to the subject of this article.

7. Edvardsen P, Odegard O. Treatment of post-traumatic clavicular pseudarthrosis. Acta Orthop Scand 1977;48:456-7.

8. Karaharju E, Joukainen J, Peltonen J. Treatment of pseudarthrosis of the clavicle. Injury 1982;13:400-3.

9. Manske DJ, Szabo RM. The operative treatment of mid-shaft clavicular nonunions. J Bone Joint Surg [Am] 1985;67-A:1367-71.

10. Pyper JB. Nonunion of fractures of the clavicle. Injury 1978; 9:268-70.

11. Rockwood CA, Green DP, Bucholz R, eds. Rockwood and Green's fractures in adults. Vol. 1. 3rd ed. New York: JB Lippincott Company, 1991:3.

12. Müller ME, Allgöwer M, Schneider R, Willenegger H. Manual of internal fixation: techniques recommended by the AO group. Second ed. Berlin, etc: Springer-Verlag, 1979. 